\title{
Considering Cognitive Traits of University Students with Dyslexia in the Context of a Learning Management System
}

\author{
Carolina Mejía $^{1}$, Alicia Díaz ${ }^{2}$, Juan E. Jiménez ${ }^{2}$, and Ramón Fabregat ${ }^{1}$ \\ ${ }^{1}$ Institute of Informatics and Applications, University of Girona, \\ 17070 Girona, Spain \\ \{carolina.mejia, ramon. fabregat\}@udg.edu \\ ${ }^{2}$ Department of Psychology and Education, University of La Laguna, \\ 38207 Canary Islands, Spain \\ \{adiazm, ejimenez\}@ull.es
}

\begin{abstract}
This paper studies the cognitive processes involved in reading among Spanish-speaking university students with dyslexia, and proposes to evaluate these processes to identify specific cognitive traits. On this basis, an automated battery for the assessment of cognitive processes was designed to be included in a learning management system (LMS). To integrate this battery into the LMS, a web service architecture that works independently of the LMS was designed. The assessment battery has been built based on a multimodal communication mechanism that delivers evaluation tasks using the visual, auditory, and speech communication channels of human-computer interaction.
\end{abstract}

Keywords: Dyslexia, cognitive traits, user model, university students, multimodal communication.

\section{Introduction}

The use of learning management systems (LMS) to support the teaching-learning process is becoming increasingly important. Therefore, it has become necessary to consider particular student characteristics, such as learning disabilities (LD), within the context of these systems. Dyslexia is a very common LD in education. It requires that teachers pay special attention and provide suitable resources to intervene with and assist affected students during their learning process.

Several studies provide examples of the work that has been done with dyslexia in children: identifying populations of children with dyslexia, evaluating their cognitive processes to determine specific deficits, and creating intervention programs to address the learning deficits presented [1] [2] [3]. Many of those programs have been supported by information and communication technologies (for example, software) that tend to increase student motivation and personalize the learning process [4] [5] [6].

Our research is focused on university students with dyslexia: a population that has been studied very little according to [7] [8] [9]. In the past two decades research in this area has shown that LDs persist into adulthood [10] [11] [12]. For this reason, it 
has become necessary to study the cognitive processes that can be altered in university students and to identify the particular cognitive traits of each student and how these deficits can be treated in this population.

According to [9], appropriate tools in Spanish cannot be found to assess these cognitive processes in the population of adult dyslexics. As a result, the research conducted in [13] consisted of the Spanish adaptation of an instrument, the UGA Phonological/Orthographic Battery developed at the University of Georgia [14]. Using as references that work and the analysis made in [15] of instruments to identify LDs, we have designed and built a new battery to assess all the cognitive processes involved in reading, making use of web-based technology so that it can be integrated into a LMS using web services.

Once the battery has been integrated into an LMS, the variables corresponding to the student cognitive traits are stored in a user data model. That data model allows us to represent the information of a previously designed user model [15]. This user model is formed by four submodels: personal profile, learning style, cognitive traits, and cognitive performance. In this paper we focus on the cognitive trait submodel, designed to store the results of the evaluation of each cognitive process (phonological awareness, orthographic processing, lexical access, processing speed, verbal working memory, and semantic processing) in the LMS. Based on this user model information, we designed an architecture with some adaptation mechanisms for intervention and assistance tasks in an LMS for students that present some type of cognitive deficit, to improve their cognitive and academic performance, and to personalize the learning process according to the specific cognitive traits of each one of them.

This paper is structured as follows. In the second section we explain what is generally considered to be dyslexia (or reading disabilities) and the cognitive processes involved in reading. The third section proposes an assessment battery for those cognitive processes. In the fourth section a user model based on student cognitive trait information is presented. Finally, in the fifth section we draw some conclusions and enumerate proposals for future work.

\section{Dyslexia: Learning Disabilities in Reading}

Reading is considered the basis of the educational process since most of the knowledge transmitted during academic development relies on the written language. That is why, from the very first years of schooling, learning to read correctly is considered a basic tool for academic development. Furthermore, when we refer to reading as the basis of the educational process, we mean it not only in terms of academia but also the importance it has in a general sense. The way we access most of the information in our environment is also connected with written language because we are immersed in the so-called information society, where activities (including productive, economic, educational, and cultural ones) are regulated through communication and information. And learning to read correctly is essential for the development of the individual in this society. When students have difficulty acquiring this skill, their academic performance and general personal development are affected. These consequences make it necessary to study the reading disabilities (RD) also known as dyslexia. 
The most accepted definition of the term dyslexia was proposed by [16]: "Dyslexia is a specific learning disability that is neurobiological in origin. It is characterized by difficulties with security and/or fluent word recognition and by poor spelling and decoding abilities. These difficulties typically result from a deficit in the phonological component of language that often is unexpected in relation to other cognitive abilities and the provision of effective classroom instruction. Secondary consequences may include problems in reading comprehension and reduced reading experience that can impede growth of vocabulary and background knowledge." According to this definition, dyslexia is an LD that may pose a number of difficulties in the various processes involved in reading.

The acquisition and development of reading depends on two types of factors: external and internal. External factors refer to the presence of a tutor/teacher who conducts sequential reading instruction; unlike oral language, reading requires formal teaching by an instructor. Internal factors refer to the development of certain cognitive processes that facilitate reading. These processes include phonological awareness, orthographic processing, lexical access, processing speed, semantic processing, and working memory.

- Phonological awareness is the ability to separate the units into which speech can be divided: the phonemes or sounds that make up the words. This is a major deficit in dyslexia and is characterized by difficulty in acquiring, consolidating, and automating phonological processes [17].

- Orthographic processing involves recognizing the word as an orthographic pattern and retrieving its pronunciation from memory (via the visual route). Although research in this process has received less attention than phonological processing [13], it is important to note that people with dyslexia present a deficit in orthographic processing [18], probably due to a deficit in phonological processing [12] [19].

- Lexical access is the process involved in obtaining the meaning of written words. This can occur over two routes [20]: one that directly connects graphic signs with meaning (visual route) and another that transforms the graphic signs into their corresponding sounds and uses those sounds to access the meaning (phonological route). This process is essential for proper reading performance and its impairment is considered a major deficit in dyslexia [21].

- Processing speed refers to the speed in which stimuli are processed. Slowness in naming familiar visual stimuli may be related to dyslexia [22] [23]. When a person reads a series of processes similar to those carried out in tasks measuring processing speed (attention to the stimulus, visual processes, access and retrieval of phonological labels, activation and integration of semantic information, etc.) are required.

- Working memory is the ability to temporarily retain information in memory, work with it or operate on it, and produce a result. Working memory is important in reading because readers have to decode and recognize words as they remember the meaning of what they have read. It has been suggested that the underlying deficit in dyslexia is in verbal working memory and that that can be attributed to difficulties accessing or using phonological structures [24]. 
- Semantic processing refers to understanding and interpreting written information. This processing involves the extraction of meaning from text and the integration of information in memory. This process involves readers' background knowledge about what they are reading (a text), which will facilitate a mental representation of the entities evoked by the text [25].

All these processes are essential for reading comprehension to be successful.

\section{Assessment Battery for Cognitive Processes}

For students with dyslexia, conducting a proper diagnosis, and understanding what their real deficits are requires a thorough analysis of their problem. Tests to detect deficits must be administered and the results studied to establish the foundations upon which different learning adaptations can be based to achieve personalized learning. To enhance the learning process, it is important to identify students' cognitive traits. We focus on detecting cognitive traits associated with dyslexia, and take into account the failure of specific cognitive processes involved in reading to design and build an assessment battery that detects deficits in the cognitive processes mentioned in the previous section.

The battery involves tasks to assess phonological awareness, orthographic processing, lexical access, processing speed, verbal working memory, and semantic processing, all of which are necessary to identify dyslexia in university students. Our purpose is to create a complete battery that assesses all cognitive processes involved in reading using web-based technology so that it can be integrated into an LMS using web services.

The battery has a modular design (see Fig. 1) to facilitate interaction between the different modules. For each type of battery user a different interface is presented depending on the permissions and tasks that can be developed. Figure 1 presents the architecture of the battery illustrating the components and their relationships. The components are: 1) assessment modules, 2) management modules, 3) a web server that stores the modules and allows communication between users and the battery by means of a browser, and 4) a database where the data from the users, results, history, etc. can be stored.

The battery has eight modules, each one designed with functions for each user type. Since the battery is a software tool designed to be used in the university context, we identified three types of users in this context: Experts, or users responsible for performing activities related to the creation of tasks, the evaluation of each cognitive process, the definition of the guidelines to present the results of students and teachers, the provision of recommendations that teachers could follow for each student with cognitive deficits, and the checking of student results; Teachers, or users responsible for scheduling and activating the battery in their classes, checking the results report of the students, and viewing the recommendations given by experts for each student with cognitive deficits; and Students, or users that complete the battery evaluation tasks (activated by the teachers) and check their results report. 


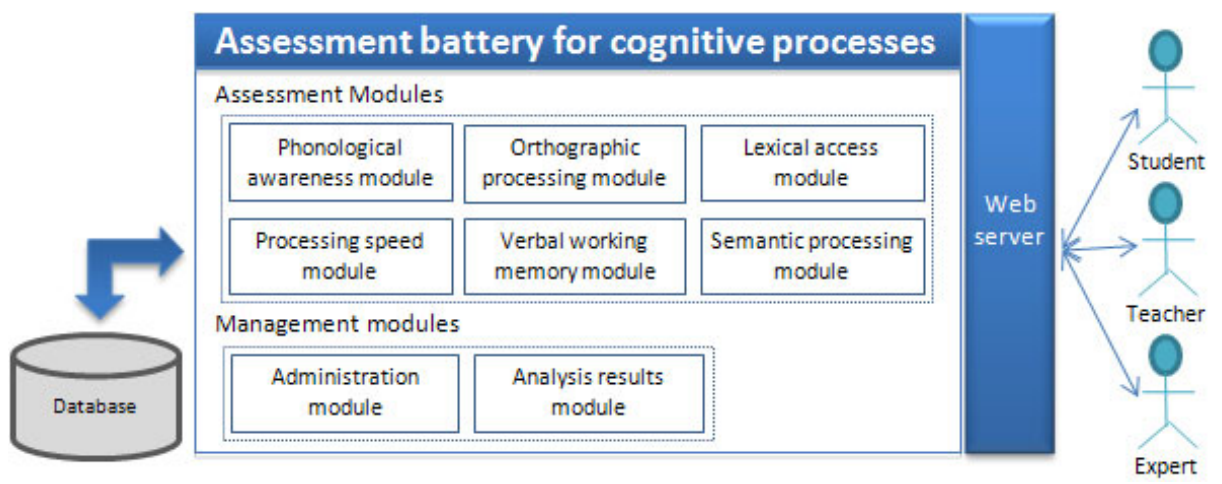

Fig. 1. Architecture of the assessment battery for cognitive processes

The assessment modules (see Fig. 1) are independent modules designed to bring together the different assessment tasks for each cognitive process, as shown in Table 1. The selection of the tasks used to assess each cognitive process is based on research work carried out by some of the authors of this paper [26] [13] [6].

Table 1. Assessment tasks for each cognitive process

\begin{tabular}{|c|c|}
\hline Modules & Tasks \\
\hline Phonological awareness & $\begin{array}{l}\text { - Segmentation into syllables } \\
\text { - Number of syllables } \\
\text { - Segmentation into phonemes } \\
\text { - General rhyme } \\
\text { - Specific rhyme } \\
\text { - Phonemic location } \\
\text { - Omission of phonemes }\end{array}$ \\
\hline Orthographic processing & $\begin{array}{l}\text { - Homophone/pseudohomophone choice } \\
\text { - Orthographic choice }\end{array}$ \\
\hline Lexical access & - Reading words and pseudowords \\
\hline Processing speed & - Visual speed test \\
\hline Verbal working memory & - Verbal working memory test \\
\hline Semantic processing & - Reading expository and narrative texts \\
\hline
\end{tabular}

To implement the tasks shown in Table 1 we rely on a multimodal architecture [27] that allows the student to communicate with the battery through different modes according to the specific objective of each assessment task. The tool uses modes of interaction for inputs and outputs that allow the combined use of spoken and written language and other devices like the keyboard and the mouse. Figure 2 depicts the channel alternatives for communication between the student and the battery.

For student information input, the battery includes an automatic component of speech recognition that converts human speech into syllables or individual words, insertion of written words and characters for specific commands and use of the mouse 
device. The battery gives students instructional output information or guidance (data output) using output mechanisms such as text on screen, graphical representation, recorded audio, and synthesized voice.

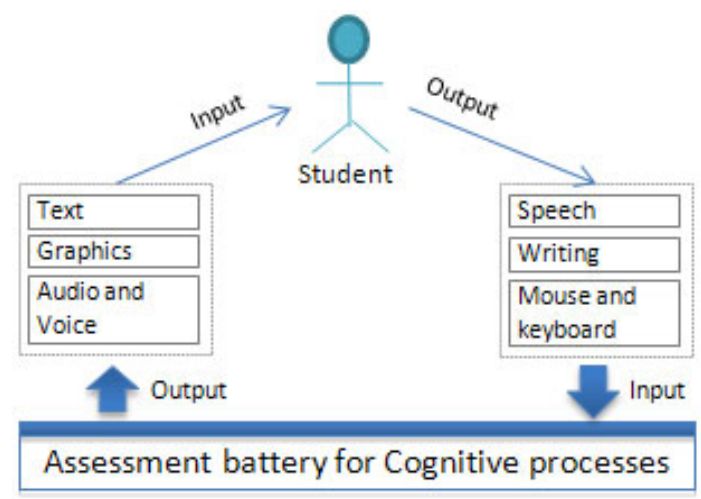

Fig. 2. Multimodal communication input and ouput

Management modules (see Fig. 1) are designed to facilitate the tool's administration and use and the analysis of results by specialists (user type: experts). The administration module is designed and implemented for the exclusive use of a subject matter expert (psychologist, pedagogue, or counselor); this module allows the creation and/or edition of different assessment tasks needed to identify cognitive deficits in students. The analysis results module is created to design and deliver the results report of the students after they have completed the assessment tasks. It automatically generates an individual report for each student with: 1) the overall cognitive performance, 2) the identification of specific cognitive deficits present, 3) the diagnosis of the presence or absence of dyslexia, and 4) some recommendations to follow in each particular case. This module can be accessed by experts, teachers, and students: experts who are responsible for the content of the reports to be delivered, teachers who wish to know student results and recommendations for each case, and students that want to see their personal result report.

The battery has been designed considering the use of standard technology and characteristics of reusability, interoperability, accessibility, and extensibility, to facilitate its integration into the structure of an LMS.

\section{Student's Cognitive Traits Model}

The user model we propose corresponds to information related to students' cognitive traits that can be stored and used in the LMS. This model is one of the four submodels of a main user model presented in [15]. The cognitive trait model identifies variables related with each aforementioned cognitive processes, allowing us to represent information about the student's LD. Descriptions of some of the elements of this model can be matched and related with the guidelines of the IMS Accessibility for Learner Information Profile Specification (IMS-AccLIP) [28]. 
The identified variables allow student information corresponding to each cognitive process assessed with the battery to be stored in the LMS (see Fig. 3). These variables have assigned the results of each of the assessment exercises from the tasks described in Table 1 and let to know whether or not students have a cognitive deficit. These results include the time students take to solve each exercise, right and wrong answers and other information particular to each task.

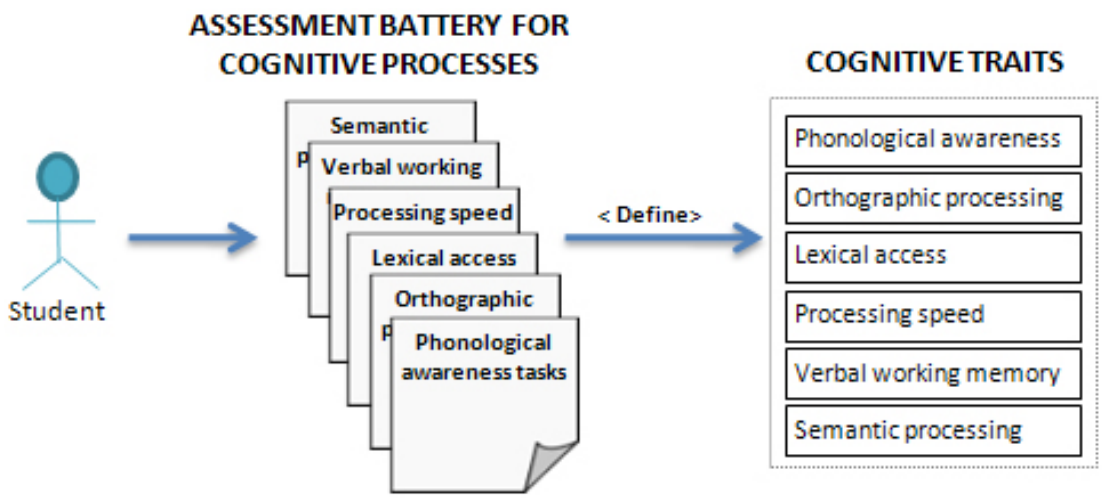

Fig. 3. Cognitive traits model

Whether or not a student has a specific cognitive deficit can be determined by calculating the scales of each assessment task performed by that student. To carry this out, a representative population of university students from different academic programs and levels will be convened to complete all the assessment tasks in the battery. Then, the results of the university student sample will be used to calculate the means, standard deviations, and percentiles, and a table of scales will be defined to identify how successfully each task confirms the presence or absence of a cognitive deficit.

Based on this information from the user model, we designed an architecture with adaptation mechanisms to intervene with and assist, through an LMS, students that present some type of cognitive deficit, in order to improve their cognitive and their academic performance. The proposed adaptation mechanisms for intervention tasks are based on adaptive methods for visual, auditory, and speech multimodal communication channels. Many studies regarding the training of cognitive processes [29] [30] [31] [32] indicate that student performance can be improved significantly if intervention tasks use both acoustic and visual modalities. Moreover, the use of assistive technology (for example, speech recognition systems, screen readers, talking spell checkers, and proofreading programs) [33] [34] is considered for personalized assistance tasks.

In summary, the design of the architecture considers: 1) a user model formed by the four previously mentioned submodels (personal profile, learning style, cognitive traits, and cognitive performance), 2) some accessibility guidelines for students with dyslexia [35], 3) e-learning standards, especially those related to the storage of the user model information [36], and 4) an adaptation engine that handles the delivery of 
contents and tasks adapted to the particular needs and preferences of students with dyslexia. The adaptation engine has adaptation rules that can be applied to personalize the intervention and assistance tasks that students complete to improve their cognitive performance. These rules will be evaluated considering the type and difficulty level (easy, medium and hard) of the task as well as the appropriate support tools, depending on the specific deficit of each student.

\section{Conclusion and Future Work}

This work aims to provide tools in the context of an LMS that support the learning process of university students with dyslexia. A battery for the assessment of cognitive processes involved in reading has been designed and implemented. This battery provides teachers and specialists with guidance on intervention and assistance for students with deficits that limit their learning performance.

The battery has a modular design to facilitate communication between the modules and interaction between users and the tool. Moreover, the battery's tasks are supported by a multimodal architecture that allows students to communicate with the battery through different modes (visual, auditory, and speech) according to the specific objective of each assessment task.

In future work the battery will allow us to retrieve the scales of each assessment task completed by university students. With those scales the battery will automatically identify whether or not the student presents a cognitive deficit. Furthermore, we will design and develop adaptation mechanisms in an LMS to provide suitable resources to intervene with and assist affected students during their learning process.

Acknowledgments. The authors would like to thank the Spanish Ministry of Science and Innovation for financial support through the A2UN@ project (TIN2008-06862C04-02/TSI). Thanks to the Scholarship Programme of the University of Girona, reference BR08/09.

\section{References}

1. Nicolson, R.I., Fawcett, A.: Automaticity: A new framework for dyslexia research? Cognition 35, 159-182 (1990)

2. Metsala, J.L.: The development of phonemic awareness in reading disabled children. Applied Psycholinguistics 20, 149-158 (1999)

3. Guzmán, R., Jiménez, J.E., Ortiz, M.R., Hernández-Valle, I., et al.: Evaluación de la velocidad de nombrar en las dificultades de aprendizaje de lectura. Psicothema 16, 442447 (2004)

4. Wise, B.W., Olson, R.K.: Computer-based phonological awareness and reading instruction. Annals of Dyslexia 45, 99-122 (1995)

5. Barker, T.A., Torgesen, J.K.: An evaluation of computer-assisted instruction in phonological awareness with below average readers. J. Edu. Comp. Res. 13, 89-103 (1995)

6. Rojas, R.E.: Diseño y validación de un videojuego para el tratamiento de la dislexia. PhD thesis, University of La Laguna, p. 606 (2008) 
7. Gregg, N.: Underserved and Unprepared: Postsecondary Learning Disabilities. Learning Disabilities Research and Practice 22, 219-228 (2007)

8. Sparks, R.L., Lovett, B.J.: College students with learning disability diagnoses: Who are they and how do they perform? J. Learn. Disab. 42(6), 494-510 (2009)

9. Jiménez, J.E., Gregg, N., Díaz, A.: Evaluación de habilidades fonológicas y ortográficas en adolescentes con dislexia y adolescentes buenos lectores. Infancia y Aprendizaje 27(1), 63-84 (2004)

10. Finucci, J.M., Gottfredson, L.S., Childs, B.: A follow-up study of dyslexic boys. Annals of Dyslexia 35, 117-136 (1986)

11. Johnson, D.J., Blalock, J.: Young Adults with Learning Disabilities. Grune \& Stratton, Orlando (1987)

12. Bruck, M.: Word recognition and component phonological processing skills of adults with childhood diagnosis of dyslexia. Developmental Review 13, 258-268 (1993)

13. Díaz, A.: Perfiles cognitivos y académicos en adolescentes con dificultades de aprendizaje con y sin trastorno por déficit de atención asociado a hiperactividad, $\mathrm{PhD}$ thesis, University of La Laguna (2007)

14. Gregg, N., Coleman, C., Stennett, R., Davis, M., et al.: Sublexical and lexical processing of young adults with learning disabilities and attention deficit/hyperactivity disorder. In: Witruk, E., Friederici, A.D., Lachmann, T. (eds.) Basic Functions of Language, Reading and Reading Disability, pp. 329-358. Kluwer Academic Publishers, London (2002)

15. Mejía, C., Fabregat, R., Marzo, J.L.: Including Student's Learning Difficulties in the User Model of a Learning Management System. In: XXXVI Conferencia Latinoamericana de Informática (CLEI 2010), Asunción, Paraguay (2010)

16. Lyon, G.R., Shaywitz, S.E., Shaywitz, B.A.: A definition of dyslexia. Annals of Dyslexia 53, 1-14 (2003)

17. Jiménez, J.E.: A reading-level match study of phonemic processes underlying reading disabilities in a transparent orthography. Reading and Writing: An Interdisciplinary Journal 9, 23-40 (1997)

18. Farmer, M., Klein, R.: The evidence for a temporal processing deficit linked to dyslexia: a review. Psychonomic Bulletin and Review 2, 460-493 (1995)

19. Share, D.C., Stanovich, K.E.: Cognitive processes in early reading development: A model of acquisition and individual differences. Issues in Education: Contributions from Educational Psychology 1, 1-7 (1995)

20. Coltheart, M., Rastle, K.: Serial processing in reading aloud: Evidence for dual-route models of reading. J. Exper Psych.: Hum. Perc. Perf. 20(6), 1197-1211 (1994)

21. Jiménez, J.E., Hernández-Valle, I.: Word identification and reading disorders in the Spanish language. J. Learn. Disab. 32, 267-275 (2000)

22. Fawcett, A.J., Nicolson, R.I.: Naming speed in children with dyslexia. J. Learn. Disab. 27, 641-646 (1994)

23. Wimmer, H., Mayringer, H., Landerl, K.: The double-deficit hypothesis and difficulties in learning to read a regular orthography. J. Educ. Psych. 92(4), 668-680 (2000)

24. Bar-Shalom, E.G., Crain, S., Shankweiler, D.: A comparison of comprehension and production in good and poor readers. Applied Psycholinguistics 14, 197-227 (1993)

25. Fayol, M.: A propos de la compréhension. In: ONL (ed.): Regards sur la lecture et ses apprentissages, pp. 85-102. Montluçon (1995).

26. Jiménez, J.E., Antón, L., Díaz, A., Estévez, A., et al.: Sicole-R: Un sistema de evaluación de los procesos cognitivos en la dislexia mediante ayuda asistida a través del ordenador [Software]. University of La Laguna (2007) 
27. W3C Multimodal Interaction Framework, W3C NOTE (May 06, 2003), http: / /www.w3 .org/TR/2003/NOTE-mmi-framework-20030506/

28. IMS Learner Information Package Accessibility for LIP, Version 1.0 Final Specification, IMS Global Learning Consortium, Inc. (2003), http: / /web4all.atrc.utoronto.ca/IMS_docs / IMS 20 ACCLIP\%20documents / imsacclip_usecasesv1p0.pdf

29. Mayer, R.E., Moreno, R.: A split-attention effect in multimedia learning: Evidence for dual processing systems in working memory. J. Educ. Psych. 90, 312-320 (1998)

30. Brünken, R., Steinbacher, S., Plass, J.L., Leutner, D.: Assessment of cognitive load in multimedia learning using dual-task methodology. Experimental Psychology 49(2), 109$119(2002)$

31. Mayer, R.E., Fennell, S., Farmer, L., Campbell, J.: A personalization effect in multimedia learning: Students learn better when words are in conversational style rather than formal style. J. Educ. Psych. 96, 389-395 (2004)

32. Holzinger, A., Kickmeier-Rust, M., Wassertheurer, S., Hessinger, M.: Learning Performance with Interactive Simulations in Medical education: Lessons learned from results of learning complex physiological models with the HAEMOdynamics SIMulator. Computers \& Education 52(1), 292-301 (2009)

33. Lancaster, P.E., Schumaker, J.B., Deshler, D.D.: The development and validation of an interactive hypermedia program for the teaching a self-advocacy strategy to students with disabilities. Learning Disability Quarterly 25, 277-302 (2002)

34. Mejia, C., Fabregat, R.: Towards a Learning Management System that Supports Learning Difficulties of the Students. In: XI Simposio Nacional de Tecnologías de la Información y las Comunicaciones en la Educación (CEDI 2010), Valencia, Spain (2010)

35. WAI Web Accessibility Initiative, W3C, http: / / www.w3 .org/WAI / intro/people-use-web.php

36. IMS Global Learning Consortium, http: / /www.imsglobal.org/specifications.html 